\title{
Active structures as deduced from geomorphic features: a case in Hsinchu Area, northwestern Taiwan
}

\author{
Yue-Gau Chen ${ }^{\mathrm{a}, *}$, J. Bruce H. Shyu ${ }^{\mathrm{b}}$, Yoko Ota ${ }^{\mathrm{c}}$, Wen-Shan Chen ${ }^{\mathrm{a}}$, Jyr-Ching $\mathrm{Hu}^{\mathrm{a}}$, \\ Bor-Wen Tsai ${ }^{\mathrm{d}}$, Yu Wang ${ }^{\mathrm{a}}$ \\ a Department of Geosciences, National Taiwan University, No. 1, Sec 4th, Roosevelt Rd, Taipei, Taiwan, ROC \\ ${ }^{\mathrm{b}}$ Division of Geological and Planetary Sciences, Caltech, USA \\ ${ }^{\mathrm{c}}$ Yokohama National University, Japan \\ ${ }^{\mathrm{d}}$ Department of Geography, National Taiwan University, Taipei, Taiwan, ROC
}

\begin{abstract}
Two previously documented active faults in northwestern Taiwan, the Hsinchu and Hsincheng Faults, are evaluated for their earthquake hazard potential by using a Digital Elevation Model (DEM), aerial photos and field mapping. Both of these thrust faults contain active anticlines in their hanging walls based on folding of young alluvial deposits. Mapping of the Hsinchu Fault suggests the presence of numerous scarps oriented sub-parallel to the fault trace that was previously defined by projection of subsurface geology. We interpret the geometry of the surface scarps to be mainly produced by the thrust component, but in part by a lateral component of fault slip. The scarps associated with the Hsincheng Fault system are less complex and offset a flight of terraces, including the modern flood plain. A back thrust exposed 1-2 km east of the Hsincheng Fault is interpreted as linked with the main thrust. Surface deformation is only apparent south of the Touchien River, and becomes less obvious across another wrench fault system, which is linked to Hsinchu Fault in the west and extends southeastward, parallel to the Touchien River. The wrench fault system mentioned above not only offsets the Hsinchu Fault, but also divides the Hsincheng Fault into segments. The supporting evidence found for this includes pressure ridges and pull-apart sags. Two associated hanging wall anticlines are both recently active based on deformed geomorphic surfaces. Two major NE striking thrusts and one NW wrench fault system are identified, reflecting the compression stress is partitioned in this area, which might be resulted from recently influenced extension tectonics, i.e., Okinawa back-arc rifting.
\end{abstract}

(C) 2003 Elsevier Ltd and INQUA. All rights reserved.

Keywords: Active fault; Thrust fault; Wrench fault; Geomorphic features; Earthquake hazard

\section{Introduction}

Accurate mapping of active structures in Taiwan is critical for assessing their potential for future damaging earthquake. For example, the Chi-Chi earthquake that struck central Taiwan in 1999 (CGS, 1999; Ma et al., 1999; Kao and Chen, 2000; Chen et al., 2001) led to over 2300 deaths and 10 billions US\$ in economic losses. More than 40 previously identified active faults have been mapped on Taiwan (Chang et al., 1998; Lin et al., 2000). These maps usually do not consider important geomorphic evidence of recent displacements, which is particularly important for determining fault 6095

*Corresponding author. Tel.: + 886-2-2369-7648; fax: + 886-2-2363-

E-mail address: ygchen@ccms.ntu.edu.tw (Y.-G. Chen). slip rates, and credible earthquake scenarios for future events. Geomorphic features, such as fault scarps and active folds, are particularly useful where they deform young sediments (i.e., those $<100 \mathrm{ka}$ ), which can be dated in an effort to constrain the slip rates. This study is aimed at evaluating tectonic strain recorded by young geomorphic features, including fluvial terraces, fault scarps and drainage channel networks. We used the recently available $40 \mathrm{~m}$ Digital Elevation Model (DEM) of Taiwan and 1:18000 scale aerial photos to map active structures in the Hsinchu area. Furthermore, we compare these local structures to the broader stress field and morphology of the Taiwanese fold-and-thrust belt where it interacts with the extensional province defined by the Taipei Basin, and further offshore in the Okinawa Trough (Fig. 1). 


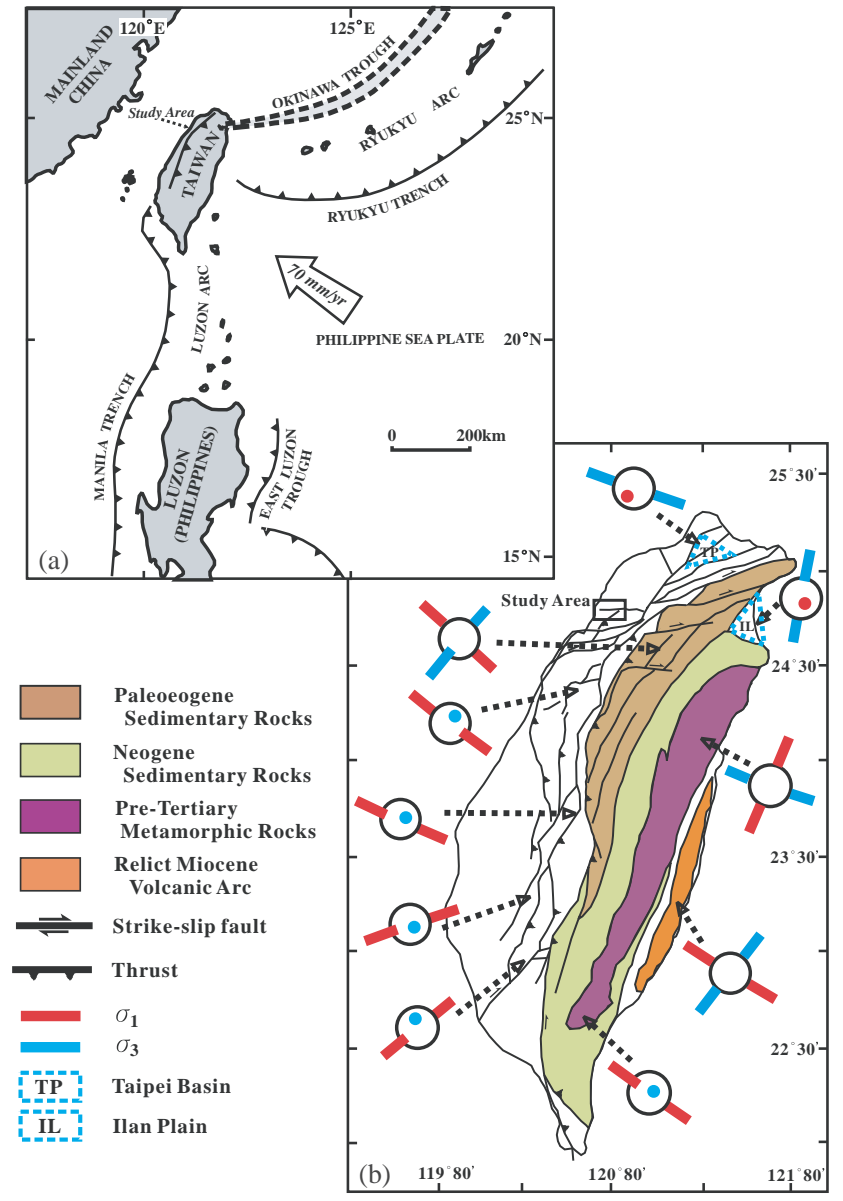

Fig. 1. (a) Current tectonic environments of Taiwan (Ho, 1982; Teng, 1990). (b) Current stress distribution of Taiwan fold-and-thrust belt. The main body of the island is undergoing compression, but both the southern and northern ends demonstrate strike-slip dominant movements. Rifting of Okinawa trough in northern Taiwan is propagating westward into northeastern Taiwan to form the on-land basins, i.e., Ilan (IL) and Taipei (TP).

\section{Tectonic background}

Taiwan is located at the junction of two arc-trench systems (Fig. 1a). The Ryukyu arc is located to the north where the Philippine Sea plate is subducted beneath the Eurasian continental plate and associated with back-arc rifting hindward the volcanic arc (i.e., the Okinawa Trough, Letouzey and Kimura, 1985; Sibuet et al., 1987). The extensional region defined by the Okinawa Trough extends westward onto northwestern Taiwan where it is dominated by normal faults and extensional basins near Taipei. This province directly abuts the northern end of Taiwan fold-and-thrust belt that is formed due to the arc-continent collision, caused by subduction of the South China Sea plate underplating the Philippine Sea plate. Shortening in the fold-andthrust belt began at 5-6 ma (Ho, 1982; Teng, 1990) and propagated westward as the Luzon volcanic arc became accreted onto the eastern edge of the belt (Suppe, 1984).
Northern Taiwan thus offers an opportunity to examine the structures that are accommodating the modern interaction between two arc/trench systems oriented at right angles to each other. Previous studies have argued the compression has waned in northern Taiwan which is located to the north of the point where the Luzon arc is actively colliding with the thrust belt (Teng, 1996; Wang et al., 1999). In addition, the rifting of the Okinawa Trough obviously imposes on northernmost Taiwan, leading to recently developed extension basins, i.e., Taipei Basin and Ilan Plain (Fig. 1a; Teng and Lee, 1996). We argue however that both active extension and contraction occurs in northern Taiwan and that principal stress changes their orientation dramatically in this region (Lu, 1994; Fig. 1b). Focal mechanisms of recorded earthquakes and GPS vectors both suggest this abrupt change in the modern stress field in northern Taiwan (Yeh et al., 1991). This change has been also argued by studies of structure geology (Lee and Wang, 1987, 1988), which suggest long-term (i.e., Pleistocene) deformation consistent with structures produced in the Late Quaternary. Our study area, Hsinchu, is located in the mountain front of northwestern Taiwan next to the northern extensional region. The evolution of the active structures provides another opportunity to further examine the recent stress field.

\section{Active faults and recent slips in Hsinchu}

Structures in our study area include two emergent thrusts (Hsinchu and Hsincheng Faults) and their associated hanging wall anticlines (Chingtsaohu and Poshan) (CPC, 1974, 1978; Suppe and Namson, 1979; Yang et al., 1994, 1996; Fig. 2b). The Hsinchu and Hsincheng Faults splay beneath the modern channel. The frontal Hsinchu Fault strikes and is a reverse fault with a substantial strike-slip component (Pan, 1965; Lin et al., 2000). The fault trace emerges from the coast, extends along the edge of the mountain front, crosses the Touchien River (Meng, 1965), and extends eastward into dissected uplands. It dips $50-60^{\circ}$ south (Chiu, 1970; Chang, 1972) and accommodates $250-700 \mathrm{~m}$ of stratigraphic separation according to well data (Chiu, 1970; Tang and Hsu, 1970). Subsurface fault-structure image is complicated and is defined by two or three imbricated shear planes developed along a pre-existing normal fault (Yang et al., 1994, 1996; Fig. 2b), indicating a stress change in tectonic history. The surface outcrop of the fault has not been documented before, nor has an age datum being determined. Only one single outcrop close to the fault scarp showing nearly upright bedrock has been reported (Tang, 1968).

The Hsincheng Fault is located on the hanging wall of the Hsinchu Fault where it is exposed as a low-angle thrust (Torii and Yoshida, 1931). It soles into the 


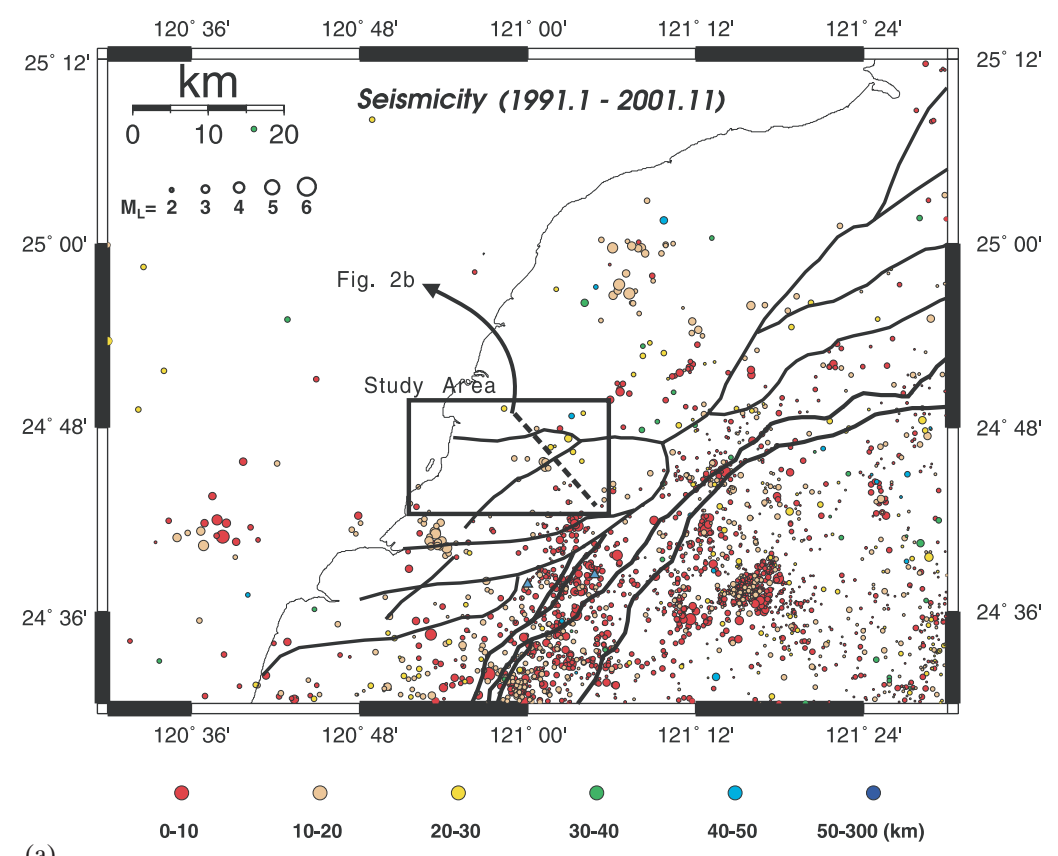

(a)

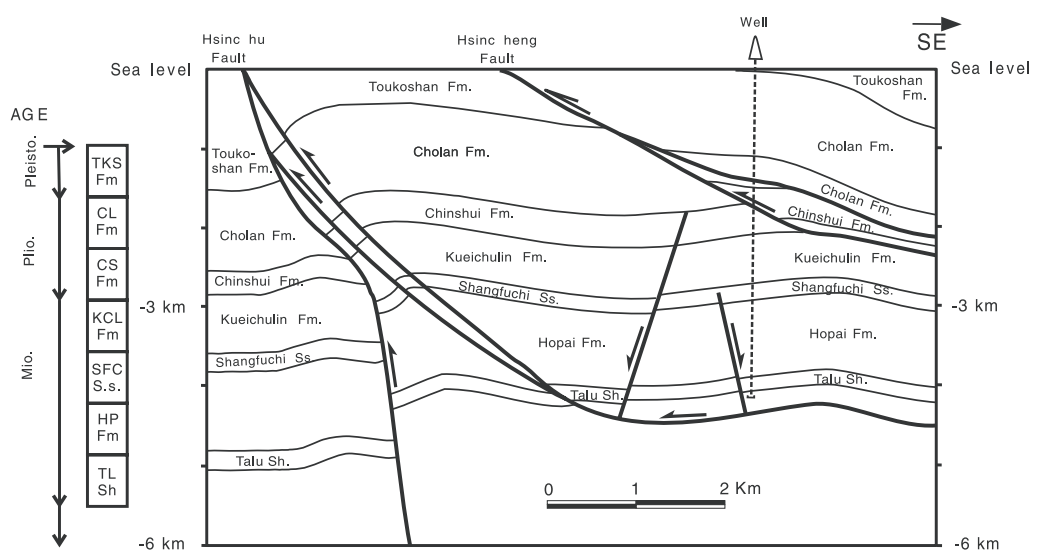

(b)

Fig. 2. (a) Seismicity distribution of northwestern Taiwan. Data are courtesy of Central Weather Bureau, R.O.C and were collected during 19912001. The study area is located in a region of lower historic seismicity. (b) A transverse seismic profile of the study area, showing two thrust faults and fault related folds in their hanging wall. Hsinchu Fault is reactivated from a preexisting normal fault. The eastern Hsincheng Fault is generated from a shallower horizon.

Chinshui Shale, a common decollement level in central Taiwan but shallower than that of the Hsinchu Fault (Namson, 1984; Yang et al., 1994, 1996; Fig. 2b). The fault-plane dips around $40^{\circ}$ southeast and accommodates $450-700 \mathrm{~m}$ of stratigraphic separation (Tang and Hsu, 1970; Chen, 1974). The fault-trace strikes roughly NE to SW and splays from Hsinchu Fault at the Touchien River. Numerous outcrops on the Hsincheng Fault have been documented that describe the style of faulting (Hsu and Chang, 1979; Huang, 1984; Lu et al., 2000). In addition, earlier geomorphological studies argued for evidence of Pleistocene activity on the Hsincheng Fault (Tan, 1934; Ku, 1963; Shih et al., 1985; Chang et al., 1999). However, no reliable age constraints for offset Late Quaternary alluvial deposits were available prior to our study.

As a result of earlier work, both of the Hsinchu and Hsincheng Faults are categorized as active but were not included in the group of most active faults because Holocene offset had not been previously identified (Chang et al., 1998; Lin et al., 2000). Since ten steps of terraces have been reported in this area (Shih et al., 1985; Chang et al., 1999) and the youngest one has been offset by the above mentioned two faults, detailed mapping of fault traces and terrace distribution would let us understand more concerning recent slip activity before we complete the chronological study. In terms of background seismicity, it seems that the Hsinchu 
area has been less distributed in the past ten years (Fig. 2a). So far we neither have geodetic data to detect the creeping strain along the fault trace, nor paleoseismological studies to recognize their coseismic displacements. Nevertheless, measurement of the total strain accumulated on geomorphic features is the best method to constrain the long-term slip rate, which is the basis to further understand the coseismic behavior.

\section{Mapping geomorphic features}

Shaded relief maps and relevant 3-D models show abundant geomorphic features associated with recent movement of the active structures in the study area (Figs. 3 and 8). The features include the terrace surfaces, their related rivers, fault scarps, and drainage channel networks developed in response to faulting and folding. The mapped terraces are unevenly distributed on both sides of the Touchien River and are mostly preserved along its southern bank. Based on restorations of the terrace surfaces, they can be divided into five steps (I, II, III, IV, and V in Fig. 4) instead of ten steps as suggested by previous studies (Shih et al., 1985; Chang et al., 1999). The elevations of individual terraces span a wide range where they have been deformed by active structures. Areas of higher terraces are characterized by closely spaced drainage networks and highly dissected terrace surfaces (Figs. 4 and 5). Tilting and back-tilting of terrace surfaces along the long terrace scarp are both common, especially terraces III and IV.
As well as the fault scarps cutting the terraces, we also mapped the scarps along the mountain-fronts based on their sinuosity and orientation parallel to the regional structural trend (Fig. 4). The terrace risers developed without tectonic relations were not considered in our mapping. All of the mapped scarps have been confirmed by field investigation. The suggested fault scarps are illustrated in Fig. 4 and can be divided into three groups based on the characteristic orientations. Two of them are clearly related to the major fault systems. The first group is distributed around the surrounding area of the previously reported trace of Hsinchu Fault and characterized by several rows of discontinuous scarps, trending ENE (Figs. 4, 6A and B). In the southeastern part of the study area, the second group shows two unique traces along the Hsincheng Fault and its associated back-thrust, separating the terrace II, III, and IV, trending NE (Figs. 4 and 6A-E). The third one strikes NW and is characterized by two to three continuous and parallel scarps. Also, it bounds the terraces and tilts the outer edges backwards (Figs. 4 and $7 \mathrm{a}-\mathrm{f})$. It obviously bisects the known fault systems, indicating that more than two fault systems are interplaying. As for the geomorphic surfaces, they are mainly distributed in the southern bank of the Touchien River.

Major rivers were analyzed to examine the responses of the active structures (Fig. 3). Along the Keya River, a meandering channel appears on both the hanging walls of the Hsinchu and Hsincheng Faults, and on the backlimb side of the Chingtsaohu anticline. To the south along a small stream, the Hsingkung River, the same pattern occurs at the small anticline close to the Hsinchu Fault. Upstream, across the hinge line of the

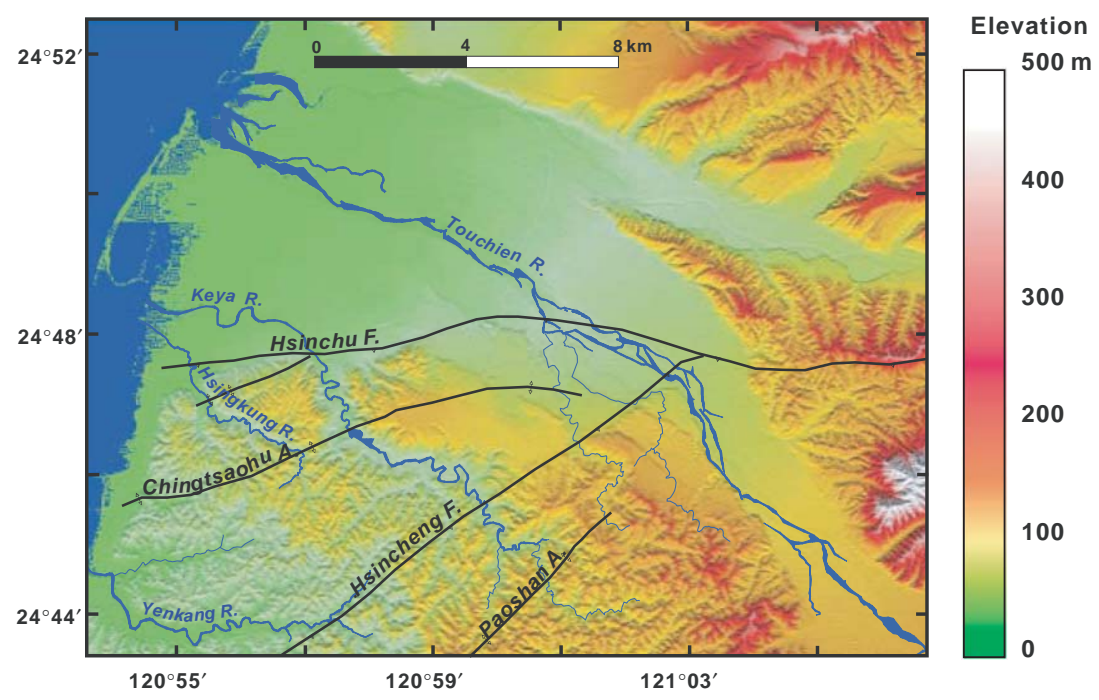

Fig. 3. Shaded relief topographic map of the study area derived from a $40 \mathrm{~m}$ DEM. The geomorphic features distributed in the southern bank of the Touchien River are closely related to major structures. Note the deflections of major drainage networks: The Hsinkung River has a dramatic turn crossing the Chingtsaohu anticline. The straight channel becomes meandering in the middle reach of the Keya River when it flows through the hinge area of Chingtsaohu anticline. The main channel and tributaries of the Touchien River are all deflected by action of the Hsincheng Fault. 


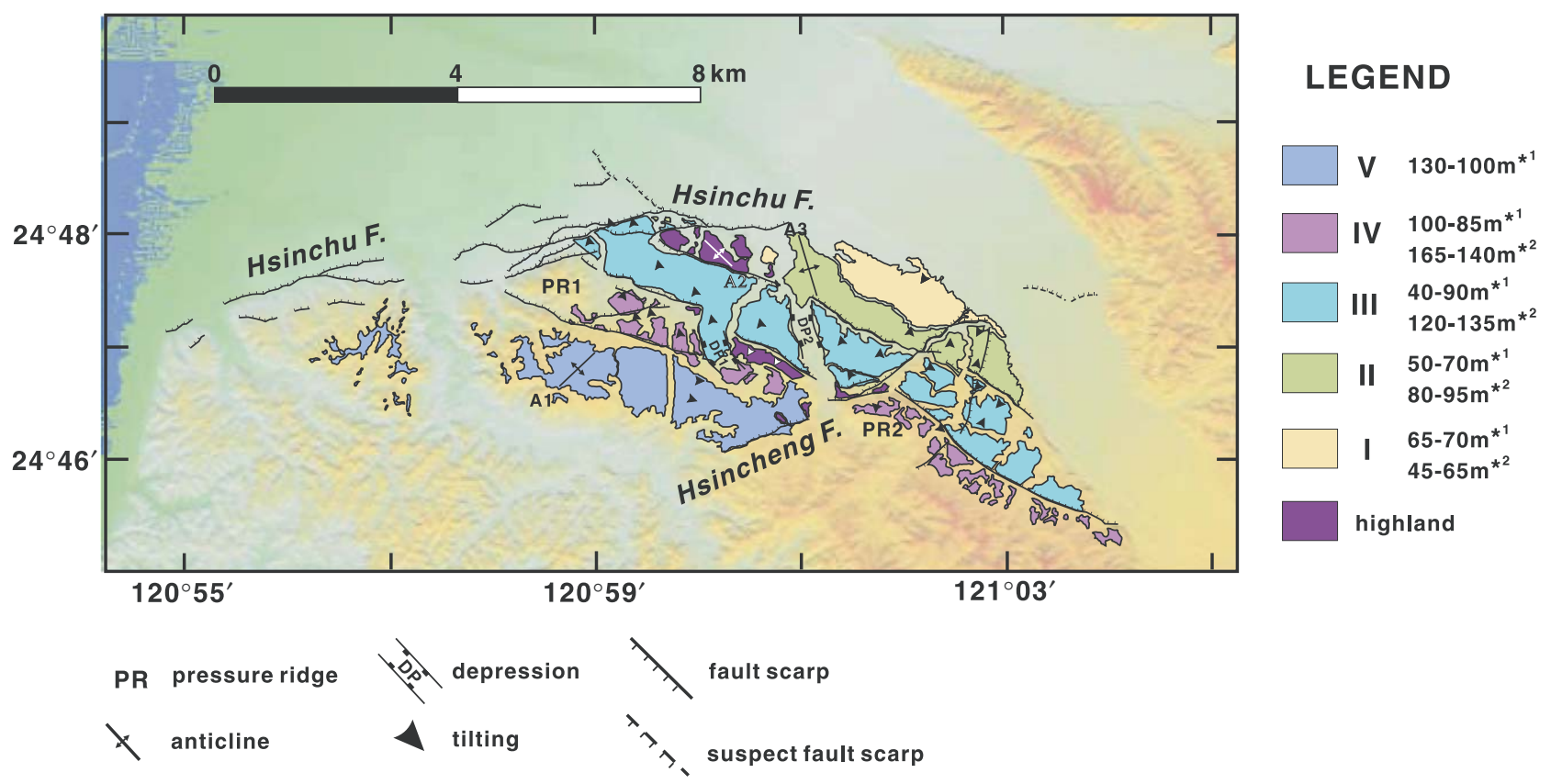

Fig. 4. Map showing the terraces and fault scarps that offset them. Due to the recent crustal deformation, the surfaces are evidently deformed, leading to various relative heights. The topographic highlands are mapped separately from the terraces to emphasize the tectonic influence on terraces. The major anticline, Chingtsaohu, is clearly recognized and marked as A1. Two small anticlines are also identified as A2 and A3 along the fault scarp of the Hsinchu Fault. Two topographic depressions (DP1 and 2) and pressure ridges (PR1 and 2) are also identified, representing the faulting of the strike-slip movement. Mapped fault scarps (solid T lines) and the suspect ones (dashed T lines) can be divided into three groups based on the orientations (see text for details). Note the back tilting is common along the scarps oriented $\mathrm{N} 60^{\circ} \mathrm{W}$, which is considered to be a newly found wrench fault system. *Marks the relative height of the terrace distributed in the hanging wall of the Hsincheng Fault.

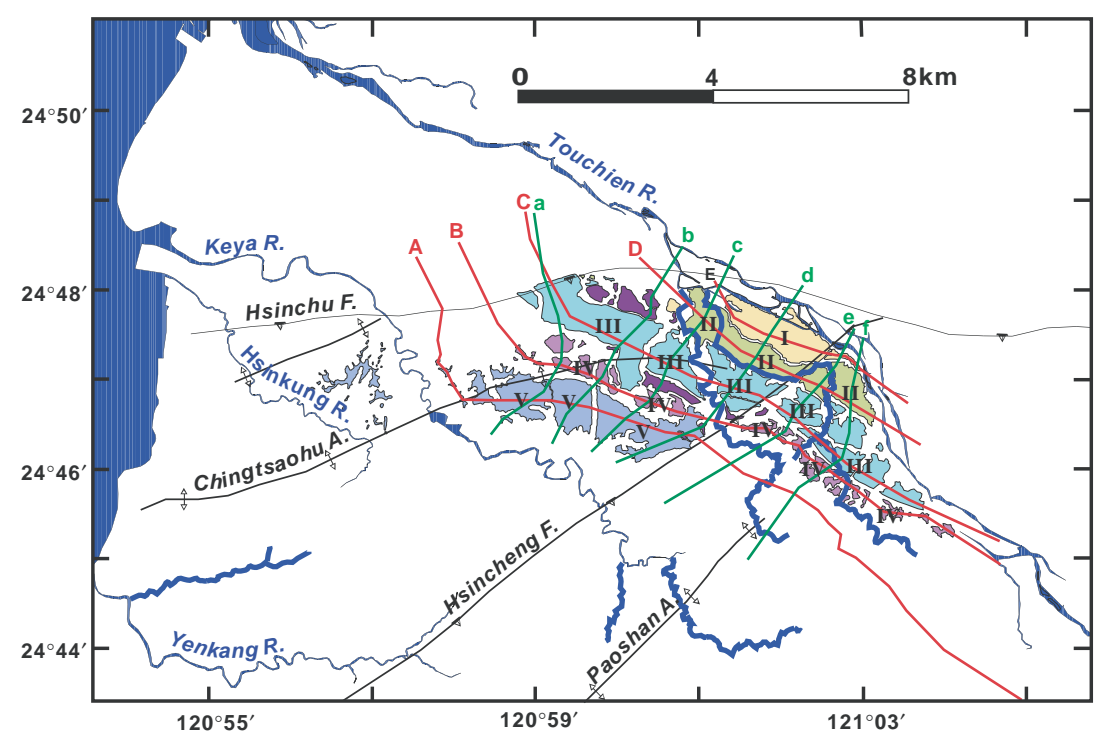

Fig. 5. Index map showing the locations of longitudinal and transverse cross-sections in Figs. 6 and 7.

Chingtsaohu anticline the river only shows a change of flow direction. With respect to the Hsincheng Fault, a promising feature is that the channels of the Touchien River and its tributaries both show deflections of flow directions across fault traces including the back-thrust. All these features indicate that the studied structures are recently active.

\subsection{Fault-related folds}

The Chingtsaohu anticline can be clearly identified by folding of the terrace $\mathrm{V}$ surface (Figs. 6A and 8). Its recent movement results in the meandering and deflection along the Keya and Hsingkung river (Fig. 3). The fold-axis derived by the folded terrace trends 
(A)

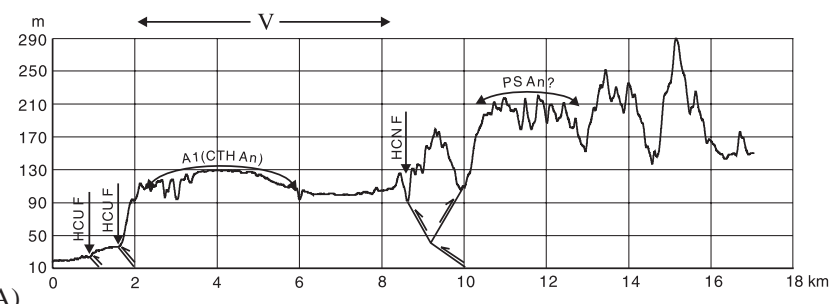

(B)
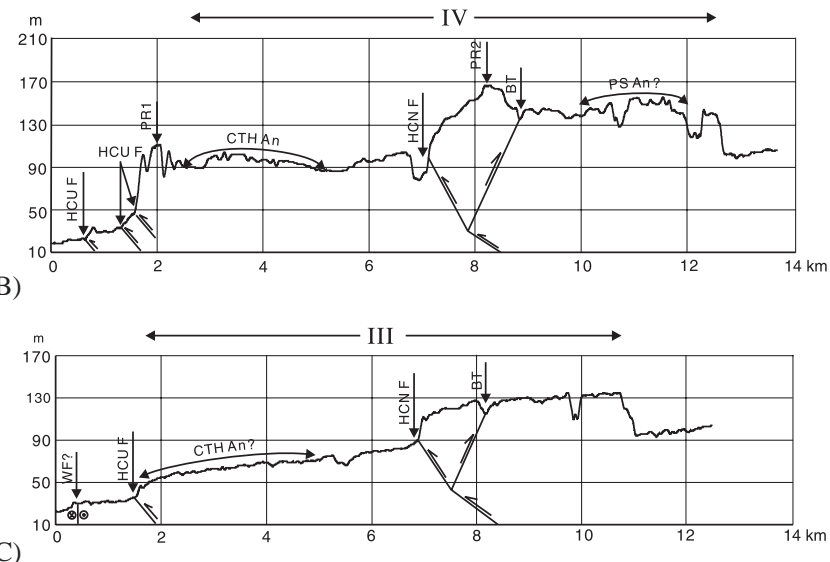

(C)

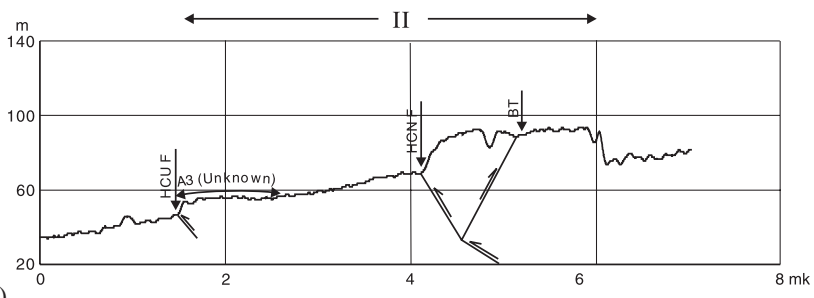

(D)

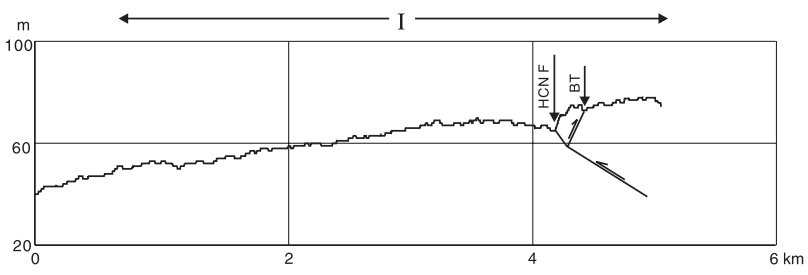

(E)

Fig. 6. Longitudinal cross-sections, measured along mapped terraces. From profiles A-E, the magnitudes of the folding and uplift decrease. The Hsinchu Fault system shows multiple scarps, while the Hsincheng Fault system is rather simple composed of a unique thrust and a back thrust. Note the major anticlines, the Chingtsaohu and Poshan, are clearly shown in the profile, and the smaller anticline, A2. In B section two pressure ridges are shown but not in the others, indicating a wrench fault is developed parallel to the profile line. Vertical exaggeration is 20 times. Subsurface structures are arbitrarily drawn to qualitatively describe their behaviors. HCU F.: Hsinchu Fault; HCN F.: Hsincheng Fault; CTH An.: Chingtsaohu anticline; PS An.: Poshan anticline; PR: Pressure ridge; BT: Back thrust; WF: Wrench fault.

ENE, parallel to the trace of the Hsinchu Fault. Folding in younger deposits across terraces IV and III is not recognizable at the resolution of the digital elevation model. Surfaces on these terraces instead dip north and may record the geometry of the plunging tip of the anticline, rather than its fore- and back-limbs.

The Poshan anticline, located in the southeastern part of the study area, can only be roughly recognized because of poorly preserved surfaces (Fig. 6A and B). Except for this, no other geomorphological evidence related to its recent movement is found. In addition, two small anticlines are found obliquely attached on the Hsinchu Fault. They are probably related to the strikeslip component of the Hsinchu Fault.

\subsection{Fault systems}

Boundaries between geomorphic surfaces are typically defined by abrupt changes in elevations, where single or multiple scarps are preserved (Figs. 3, 4 and 9). The Hsinchu Fault system partitions slip across at least two 


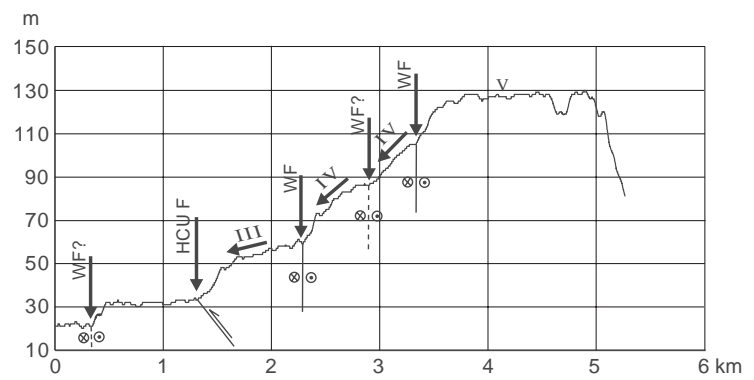

(a)

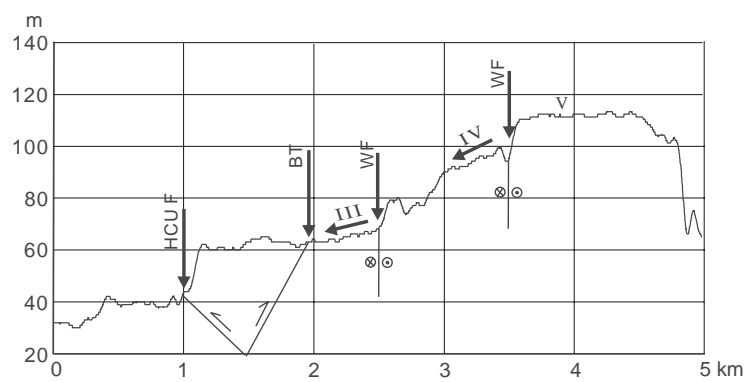

(b)

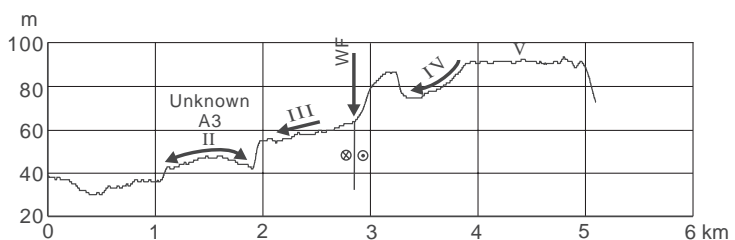

(c)

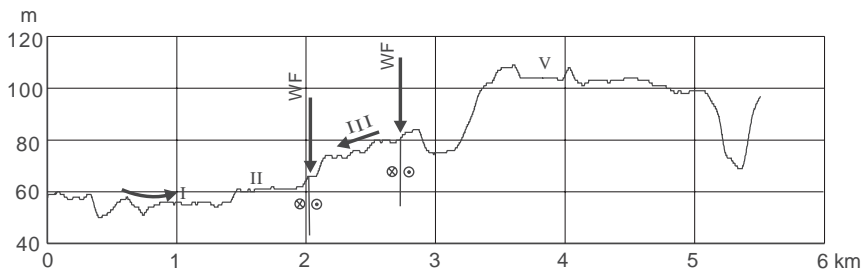

(d)

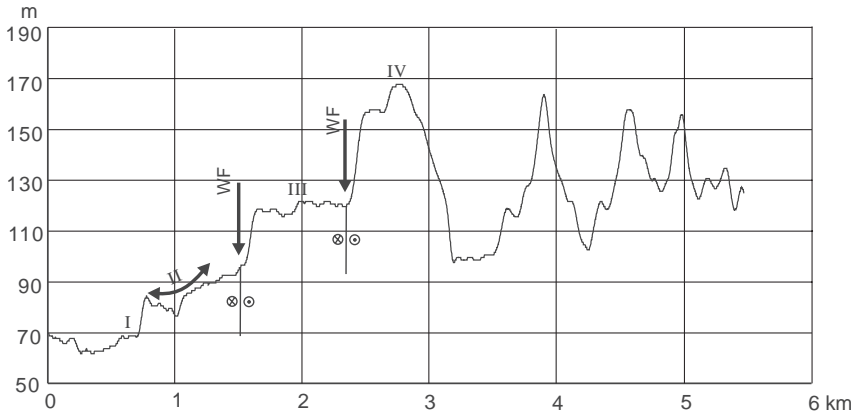

(e)

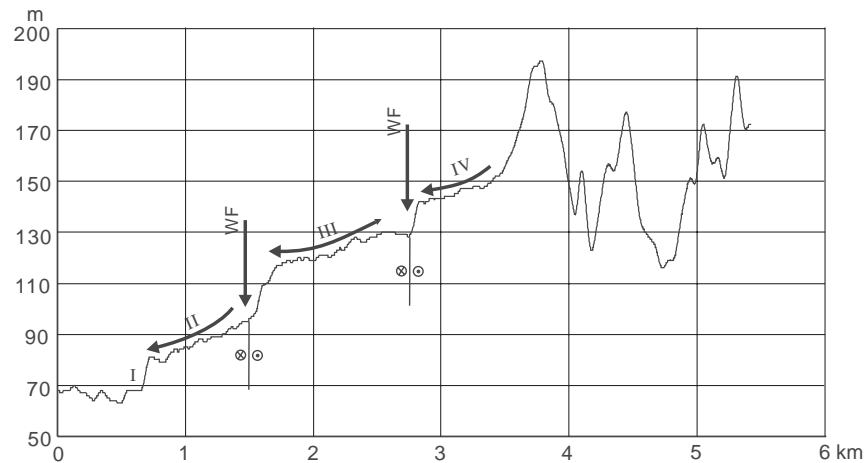

(f)

Fig. 7. Transverse cross-sections cutting through the flight of terraces at six locations from lower reach upstream. Obviously, terrace surfaces are individually affected by the active tectonics, leading to differential deformation. In particular, the surfaces are warped by back tilt associated with the faulting. Although to date there is no geologic evidence to confirm the origin of the terrace scarps, we tentatively suggest them to be fault scarps since they divide the surfaces with differential deformation. The high tilting angle of terrace IV is probably caused by axis turning of the Chingtsaohu anticline. Small anticline, A3, is also shown in profile C. Circles with a dot in the center represents the movement outward the paper and vice versa the circles with cross. The other symbols follow Fig. 6. Vertical exaggeration is 20 times.

fault-stands in the western part of the area we mapped (Fig. 4) and splits into numerous discontinuous, subparallel scarps further east near the Touchien River valley (Figs. 6A-C). Its recent movement results in the meandering developed along the Keya River (Fig. 3). The highest terraces are vertically offset over $90 \mathrm{~m}$ while the lowest one is only offset less than $10 \mathrm{~m}$ (Figs. 4, 6B and 9A). The observation that the Hsinchu Fault offsets the youngest fluvial deposits along the modern flood plain of the Touchien River suggests this fault has a recent slip history involving a number of seismic events, and that it should be classified as an active fault (Figs. 8 and 9A). The scarps are abruptly terminated at the southern channel wall of the Touchien River. There is only unclear evidence across the northern bank of the Touchien River for recent displacement of young deposits (Fig. 4). We interpret this to indicate that a wrench fault may be buried in the river valley. Another feature in the west, the hill front formed by up-throwing the hanging wall of the Hsinchu Fault, shows an indentation at the Keya River (Figs. 3, 4 and 8b). This probably implies that a wrench fault developed and tore apart the Hsinchu Fault. In addition, two topographic highlands are identified as pressure ridges since they only occurred along the suggested fault trace (PR1 and PR2 in Figs. 4 and 6B).

The Hsincheng Fault is defined by a relatively simpler scarp that offsets the terraces from IV to I with decreasing scarp heights from 58 to $5 \mathrm{~m}$. Considering the synchronous terrace, its offset is significantly larger than that of the Hsinchu Fault. The associated channel network of the Touchien River strongly reflects recent 

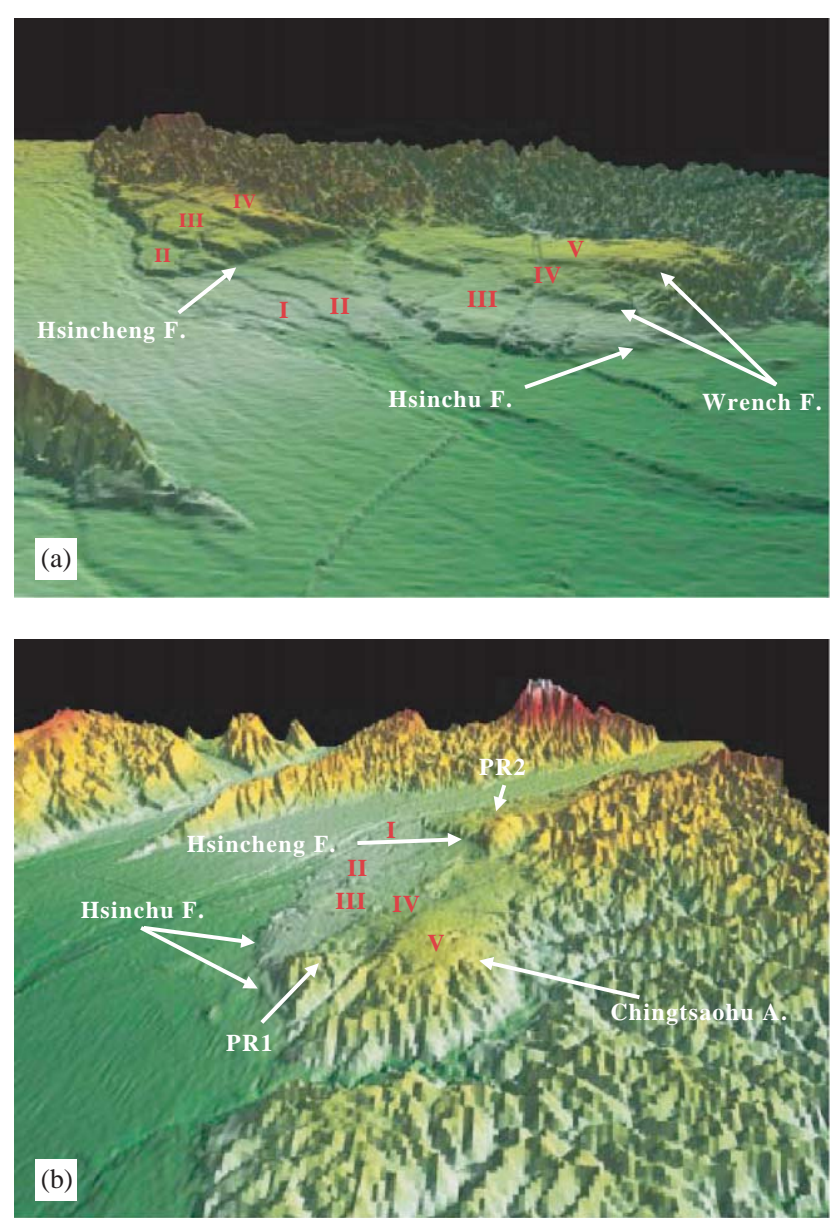

Fig. 8. Two oblique scenes showing the geomorphology of the study area.

activity (Fig. 3). Recent surface ruptures are well exposed along the Hsincheng Fault where it offsets terrace I deposits (Fig. 9B). It is worthy to note that the scarps parallel or subparallel to the Hsincheng Fault are clear only for $\sim 4 \mathrm{~km}$ along its length, which is relatively short compared to its total length measured from the geological map. Recent movement of this active segment also deflects the modern drainage network, especially the Touchien River system (Fig. 3). The fault scarp is not readily apparent to the south and north. A backthrust is clearly shown in each profile in the hanging wall of the Hsincheng Fault, which has not been previously recognized (Fig. 6). This subsidiary fault also affects the stream channel development in the highlands south of the main trace of the Hsincheng Fault (Fig. 3). The topographic highland that defines the NW trending pressure ridge (PR2 on terrace IV, Fig. 6B) is bound by the Hsincheng Fault and the associated back-thrust. This orthogonal structural highland (PR2 in Figs. 4 and 6) accommodates both shortening and lateral displacement generated by thrust fault system (i.e., the Hsincheng Fault) as well as the wrench fault that will be discussed below.
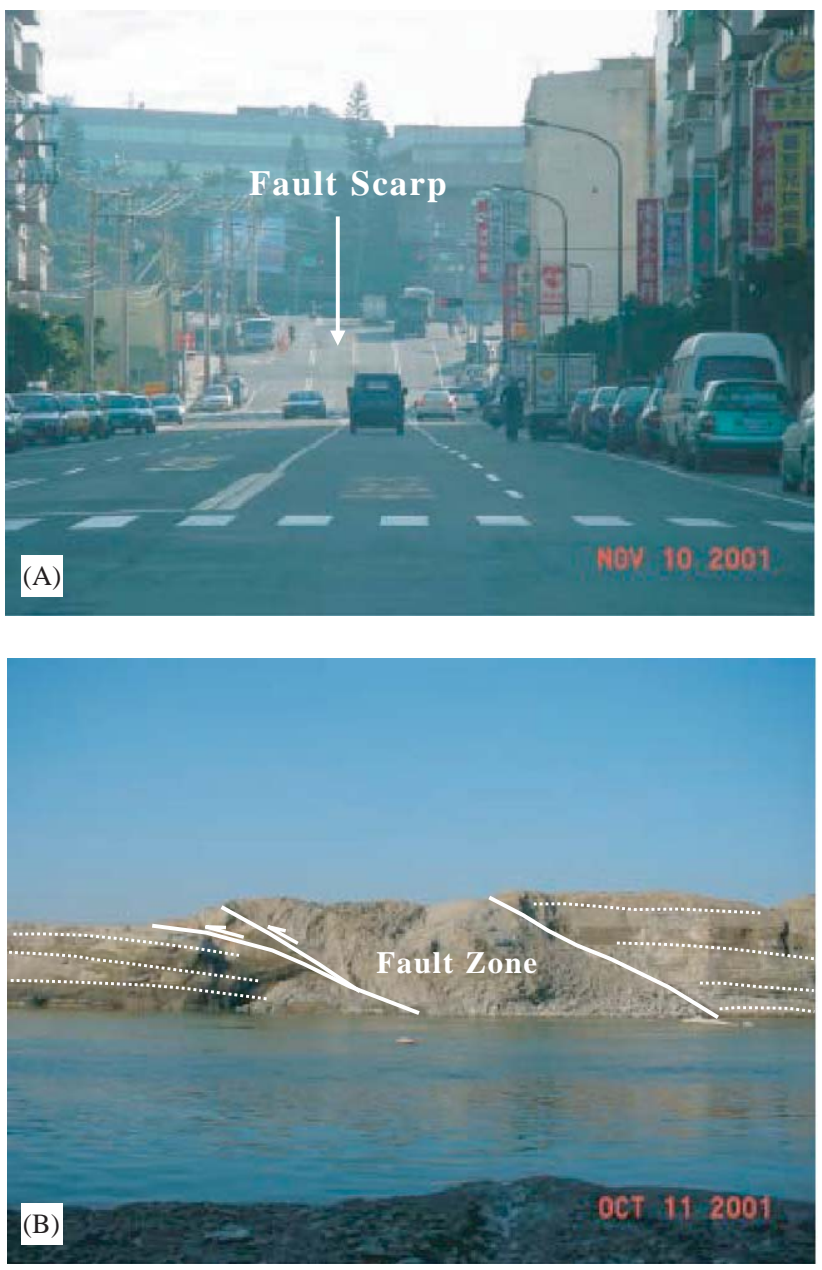

Fig. 9. (A) Photograph of the fault scarp of the Hsinchu Fault in Hsinchu City. The foundation excavation of the far building in hanging wall showed upright and brecciated bedrock, which is the only field evidence of the Hsinchu Fault. (B) Photograph of an outcrop of the Hsincheng Fault along the Touchien River. White dash-lines represent the bedding. A low angle thrust with vergence to the west reaches the ground surface with a fault zone of $4-5 \mathrm{~m}$ in width that is bound by two slip planes. The hanging wall is composed of Pliocene coastal deposits, sandstones and shales, while the footwall is the younger (Pleistocene) sandstone dominant unit that is believed to be the distal part of an ancient fan-delta created in the mountain front.

The wrench fault system mentioned above is composed of two to three parallel but discontinuous surface traces (Figs. 4 and 7). They are all generated from the Hsinchu Fault in the west and truncate the Hsincheng Fault, reaching the eastern end of the study area. It is very difficult to distinguish this structure using available seismic profiles since the profiles are deep ones worked out for petroleum exploration. Field investigation also failed to find any geologic outcrops showing faulting evidence. Nevertheless, in terms of geomorphic features, pressure ridges, back-tilting terraces and pull-apart depressions (albeit they are thought to be initiated by bending moment tensile stress associated with the Hsinchu Fault) presented in this study, such a wrench 
fault system possibly exists. It is characterized by two to three long scarps trending NNW to SSE, which were thought to be terrace risers because of their orientations parallel to the modern river (Fig. 4).

\section{Discussion}

\subsection{New wrench fault system and stress field change}

We would like to note again that the scarp distribution, both of the Hsinchu and Hsincheng Fault system, becomes unclear across the Touchien River to its northern bank. In contrast, the Hsincheng Fault shows clear features within only a few kilometers on the southern bank (Fig. 3). This implies the shortening of this segment of the Hsincheng Fault is reinforced by the action of the wrench fault system. Since the Hsinchu and Hsincheng are both old fault systems, the newly found wrench fault system might be recently developed and caused by stress turning. The Hsinchu area is located in a place where the stress changes its orientation (Fig. 1a). A previous study also addressed this point based on geometry of the major fault systems (Huang, 1987). The collision history of Taiwan suggests that the mountain belt was initiated in the north and propagated to the south (Suppe, 1984; Teng, 1990). Westward propagation of extensional structures associated with the Okinawa Trough is now interacting with the relatively slowly contracting thrust belt in northern Taiwan. The study area is contained in the area of abruptly rotated stress fields, provided by the interaction of the thrust belt and the Okinawa rifting. The complex array of thrust faults and strike-slip faults therefore accommodate slow westward propagation of the thrust belt and dextral shear as wrench faults transfer lessened shortening towards the extensional fault systems to the north. Abrupt terminations of the thrust faults and folds mapped in addition to NW-trending wrench faults support this assumption. Nevertheless, the geomorphic data presented in this study suggest the faults are all active, indicating that the shortening has waned, but still persists in the study area.

\subsection{Faulting behavior}

As previously reported, the Hsinchu Fault is a thrust with a dextral strike-slip component (Meng, 1965; Tang, 1968; Chang et al., 1998; Lin et al., 2000). The topographic depressions identified in the hanging wall are the structural grabens commonly created by bending moment tensile stresses, and occur along thrust-associated anticline (Fig. 4; Philip and Meghraoui, 1983). However, currently they are closely attached on the possible trace of the wrench faults. We therefore suggest that they are initiated by the Hsinchu Fault but are latterly controlled by the newly developed wrench fault system. The graben orientation clearly indicates the dextral slip of the Hsinchu and wrench fault. If we further treat the wrench fault as an antithetic structure, this supports the conclusion very well. However, except for these large-scale features, we did not find many meso-scale geomorphic features showing significant dextral slip. It is probable that the Hsinchu Fault is still dip-slip dominant. On the other hand, the small anticlines, A2 and A3 in Fig. 4, are also suggested to have formed under the dextral component of the thrust system.

The Hsincheng Fault has also been previously identified as a pure thrust, as supported by field evidence (Fig. 9B). However, the geomorphic evidence reveals that it was dextrally moved (Fig. 8). As shown in Figs. 3, 4 and 8 , there is a series of en echelon short scarps generated from the main fault toward due east. We believe the recent fault-slip also contains a dextral component, though it was dominated by pure thrusting in the early stage of formation. The hanging-wall back thrust shows simple scarps in the field, indicating it is dip-slip dominant.

\subsection{Major active faults}

The structure framework in our study area is built up by dual thrusts and their hanging wall developed anticline (i.e., fault-bend fold). Some of the structures are active but not entirely based on the active landforms presented in this paper. For the Hsinchu Fault, the active segment is only the southwestern half, while the Hsincheng Fault has an even shorter active segment, a few kilometers on the southern bank of the Touchien River. It is very difficult to explain the rather short active segment of the Hsincheng Fault if we consider it as a major seismogenic active fault. In contrast, the newly found wrench fault system is generated from the northern end of the active segment of the Hsinchu Fault, and continuously shows geomorphic evidence to the eastern border of the study area. We, hence, prefer to treat both this wrench fault and the southern segment of the Hsinchu Fault as essentially active fault systems. Supporting evidence comes from the hanging wall anticlines. Based on surface and subsurface geology, the fault-related anticlines, the Chingtsaohu and Poshan anticlines, are both only distributed to the south of the Touchien River (CPC, 1974, 1978; Yang et al., 1994, 1996), also indicating a structure termination along the Touchien River.

\subsection{Slip rate}

Since no paleoseismology and terrace age are currently available, it is impossible to derive the slip rates over short-term time scales. In particular, all the studied 
faults have significant strike-slip components, the toughest part to determine. In this paper, we tentatively calculate the long-term dip-slip rate of the Hsinchu and Hsincheng Faults based on the dips and vertical separation of young deposits offset by them and the age of those deposits. As revealed in the profile of Fig. 2b, accumulated dip-slips on Hsinchu and Hsincheng Fault are 900 and $1400 \mathrm{~m}$, respectively, as indicated by the offsets of the boundary between the Chinshui shale and the overlying Cholan Formation. However, the time is cannot be derived, because of indiscernible sub-units in the youngest sedimentary unit, the Toukoshan Formation, ca. $2 \mathrm{Ma}$. We therefore tentatively compute a minimum rate assuming that the commencement corresponds to the termination of deposition of the Cholan Formation, ca. $2 \mathrm{Ma}$, due to the identical thickness measured across the fault planes prior to that time. Derived dip-slip rates are 0.45 and $0.7 \mathrm{~m} / \mathrm{ka}$ for the Hsinchu and Hsincheng, respectively. Even if the rates are doubled, they are still much smaller than the Chelungpu Fault, the earthquake fault of the 1999 Chichi earthquake (Chen et al., 2001). Unless the strikeslip component is predominant in these two thrust fault systems, they seem relatively stable. Another line of evidence generally adopted in Taiwan is the youngest lateritic terrace surface. In the study area, the youngest lateritic terrace is terrace III, generally with a relative height of $40-90 \mathrm{~m}$. This height is much lower than the youngest lateritic surface documented in central Taiwan, also indicating a relative low uplift rate.

\section{Conclusions}

1. A wrench fault system is newly identified along the Touchien River by using geomorphic features, and is considered as a result of the recent change of the stress field.

2. The wrench fault system and the southern segment of the Hsincheng Fault are the major active faults. The hanging wall anticlines, back-thrust and even the Hsincheng Fault are all subsidiary active structures.

3. Both the active segments on the Hsinchu and Hsincheng Fault show recent dextral slip. The wrench fault system is also dextral.

4. The slip rates of both Hsinchu and Hsincheng Faults are relatively lower than in Central Taiwan.

\section{Acknowledgements}

This study was financially supported by National Science Council, R.O.C under Grant Number of NSC 91-2119-M-002-010. We also thank the Central Geological Survey and Central Weather Bureau, Republic of
China for their support of field work and the courtesy of providing seismicity data.

\section{References}

CGS, 1999. Investigation report of 921 earthquake geology and Map of Surface Ruptures along the Chelungpu Fault during the 1999 Chi-Chi Earthquake, Central Geological Survey, Ministry of Economic Affairs, Taiwan, Republic of China (in Chinese).

Chang, S.L., 1972. Subsurface geologic study of the Hsinchu Basin, Taiwan. Petroleum Geology of Taiwan 10, 63-87.

Chang, H.C., Lin, C.W., Chen, M.M., Lu, S.T., 1998. An introduction to the active faults of Taiwan: Explanatory text for the active fault map of Taiwan, scale 1: 500,000, Central Geological Survey, Ministry of Economic Affairs, Taiwan, Republic of China, 103p (in Chinese with English abstract).

Chang, J.C., Teng, K.H., Liu, M.C., 1999. The geomorphological study on the terraces of Tou-Chein River. Geographical Study 31, 61-81 (in Chinese with English abstract).

Chen, J.S., 1974. Seismic study of the Paoshan structure, Hsinchu, Taiwan. Petroleum Geology of Taiwan 11, 183-195.

Chen, Y.G., Chen, W.S., Lee, J.C., Lee, Y.H., Lee, C.T., Chang, H.C., Lo, C.H., 2001. Surface rupture of 1999 Chi-Chi earthquake yields insights on active tectonics of central Taiwan. Bulletin, Seismological Society of America 91 (5), 977-985.

Chiu, H.T., 1970. Structural features of the area between Hsinchu and Taoyuan, northern Taiwan. Proceedings of the Geological Society of China 13, 63-75.

CPC, 1974. The geological map of Miaoli, scale 1:100,000. Taiwan Petroleum Exploration Division Publication, Chinese Petroleum Corporation, Taiwan, Republic of China.

CPC, 1978. The geological map of Hsinchu-Taoyuan, scale 1:100,000. Taiwan Petroleum Exploration Division Publication, Chinese Petroleum Corporation, Taiwan, Republic of China.

Ho, C.S., 1982. Tectonic evolution of Taiwan - Explanatory text of the geologic map of Taiwan. Central Geological Survey, Ministry of Economic Affairs, Taiwan, Republic of China, 126p.

Hsu, T.L., Chang, H.C., 1979. Quaternary faulting in Taiwan. Memoir Geological Society of China 3, 155-165.

Huang, C.S., 1984. Quaternary faults in the coastal area between Hsinchu and Chunan, northwestern Taiwan. Vol. 3, Special Publication of Central Geological Survey, Taiwan, pp. 103-126.

Huang, F.F., 1987. Wrench faults in western Taiwan and oil-gas accumulation. Petroleum Geology of Taiwan 23, 1-12.

Kao, H., Chen, W.P., 2000. The Chi-Chi earthquake sequence: active, out-of-sequence thrust faulting in Taiwan. Science 288, 2346-2349.

$\mathrm{Ku}$, C.C., 1963. Photogeologic study of terraces in north-western Taiwan. Proceedings, Geological Society of China 6, 51-60.

Lee, C.T., Wang, Y., 1987. Paleostress changes due to the PlioceneQuaternary arc-continent collision in Taiwan. Memoir, Geological Society of China 9, 63-86.

Lee, C.T., Wang, Y., 1988. Quaternary stress changes in northern Taiwan and their tectonic significance. Proceedings, Geological Society of China 31 (1), 154-168.

Letouzey, J., Kimura, M., 1985. Okinawa Trough genesis: structure and evolution of Backarc basin developed in a continent. Marine and Petroleum Geology 2, 111-130.

Lin, C.W., Chang, H.C., Lu, S.T., Shih, T.S., Huang, W.C., 2000. An introduction to the active faults of Taiwan: Explanatory text for the active fault map of Taiwan, scale 1: 500,000, 2nd Edition, Central Geological Survey, Ministry of Economic Affairs, Taiwan, Republic of China, 103p (in Chinese with English abstract).

Lu, C.Y., 1994. Neotectonics in the foreland thrust belt of Taiwan. Petroleum Geology of Taiwan 29, 1-26. 
Lu, S.T., Shih, T.S., Lin, C.W., Huang, W.J., Chen, H.W., Lee, Y.H., Chen, Z.Y., Chang, H.C., 2000. Field investigation of active faults on Hsinchu area, northern Taiwan. 2000 Annual Meeting of the Geological Society of China, program with abstracts, Geological Society of China, Taipei, pp. 308-310 (in Chinese with English abstract).

Ma, K.F., Lee, C.T., Tsai, Y.B., Shin, T.C., Mori, J., 1999. The ChiChi, Taiwan earthquake: large surface displacements on an inland thrust fault. EOS Transactions 80, 605-611.

Meng, C.Y., 1965. Lateral movement in the northern half of western Taiwan. Petroleum Geology of Taiwan 4, 283-286.

Namson, J., 1984. Structure of the western Foothills belt, MiaoliHsinchu area, Taiwan: (III) northern part. Petroleum Geology of Taiwan 20, 35-52.

Pan, Y.S., 1965. Interpretation and seismic coordination of the Bouguer gravity anomalies obtained in the northwestern Taiwan. Petroleum Geology of Taiwan 4, 287-301.

Philip, H., Meghraoui, M., 1983. Structural analysis and interpretation of the surface deformations of the El Asnam earthquake of October 10, 1980. Tectonics 2, 17-49.

Shih, T.T., Teng, K.H., Chang, J.C., Yang, G.S., 1985. The active faults and geomorphic surfaces of Chutung Tableland in Taiwan. Geographical Studies 9, 1-14 (in Chinese with English abstract).

Sibuet, J.C., Letouzey, J., Barbier, F., Charvet, J., Fourcher, J.P., Hilde, T.W.S., Kimura, M., Chiao, L.Y., Marsset, B., Mueller, C., Stephen, J.F., 1987. Back-arc extension in the Okinawa Trough. Journal of Geophysical Research 92 (B13), 14041-14063.

Suppe, J., 1984. Kinematics of arc-continent collision, flipping of subduction, and back-arc spreading near Taiwan. Memoir, Geological Society of China 6, 21-33.

Suppe, J., Namson, J., 1979. Fault-bend origin of frontal folds of the western Taiwan fold-and thrust belt. Petroleum Geology of Taiwan $16,1-18$.
Tan, K., 1934. Geomorphological study of Chikuto Plateau, Shinchikushu, Formosa. Journal of Geography 46 (539), 35-43.

Tang, C.H., 1968. Photogeological observations on the low hilly terrain and coastal plain area of Hsinchu, Taiwan. Proceedings, Geological Society of Taiwan 6, 71-79.

Tang, C.H., Hsu, C.H., 1970. Subsurface geology and petroleum deposits in the Hsinchu area. Petroleum Geology of Taiwan 7, 89-101.

Teng, L.S., 1990. Geotectonic evolution of late Cenozoic arc-continent collision in Taiwan. Tectonophysics 183, 57-76.

Teng, L.S., 1996. Extensional collapse of the northern Taiwan mountain belt. Geology 24 (10), 949-952.

Teng, L.S., Lee, C.T., 1996. Geomechanical appraisal of seismogenic faults in northeast Taiwan. Journal of the Geological Society of China 39 (2), 125-142.

Torii, K., Yoshida, K., 1931. Report of a survey of the Byoritsu and Chikuto oil fields of Shinchiku Province. Bureau of Productive Industries, Government-General of Taiwan, publication No. 585, $81 \mathrm{p}$ (in Japanese).

Wang, K.L., Chung, S.L., Chen, C.H., Shinjo, R., Yang, F.T., Chen, C.-H., 1999. Post-collisional magmatism around northern Taiwan and its relation with opening of the Okinawa Trough. Tectonophysics 308, 363-376.

Yang, K.M., Wu, J.C., Ting, H.H., Wang, J.B., Chi, W.R., Kuo, C.L., 1994. Sequential deformation in foothills belt, Hsinchu and Miaoli area: implications in hydrocarbon accumulation. Petroleum Geology of Taiwan 29, 47-74.

Yang, K.M., Wu, J.C., Wickham, J.S., Ting, H.H., Wang, J.B., Chi, W.R., 1996. Transverse structures in Hsinchu and Miaoli areas: structural mode and evolution in foothills belt, northern Taiwan. Petroleum Geology of Taiwan 30, 111-150.

Yeh, Y.H., Barrier, E., Lin, C.H., Angelier, J., 1991. Stress tensor analysis in the Taiwan area from focal mechanisms of earthquakes. Tectonophysics 200, 267-280. 